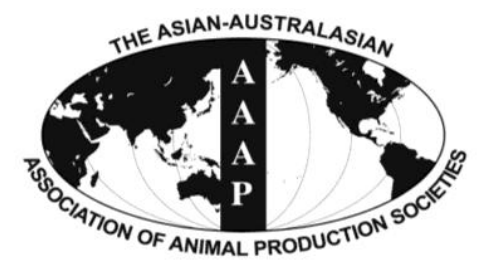

Asian-Aust. J. Anim. Sci.

Vol. 25, No. 11 : 1641-1648 November 2012

http://dx.doi.org/10.5713/ajas.2012.12260

www.ajas.info

pISSN 1011-2367 elSSN 1976-5517

\title{
Effect of Dietary Supplementation of the Combination of Gallic and Linoleic Acid in Thigh Meat of Broilers
}

\author{
Kyung Haeng Lee, Samooel Jung ${ }^{1}$, Hyun Joo Kim ${ }^{1}$, Il Suk Kim ${ }^{2}$, Jun Heon Lee ${ }^{1}$ and Cheorun Jo ${ }^{1}$ * \\ Department of Food and Nutrition, Korea National University of Transportation, \\ Jeungpyung, Chungbuk 368-701, Korea
}

\begin{abstract}
This study was performed to investigate the combined effect of dietary supplementation of gallic and linoleic acid (GL) on the antioxidative effect and quality of thigh meat from broilers. Broilers received 3 dietary treatments: i) commercial finisher diet (control), ii) $0.5 \%$ GL (gallic:linoleic acid = $1 \mathrm{M}: 1 \mathrm{M}$ ), and iii) $1.0 \%$ GL during the 22 to $36 \mathrm{~d}$. The pH value of broiler thigh meat was increased by GL supplementation. Water holding capacity of the thigh meat was enhanced by the $1.0 \%$ dietary GL supplementation. Antioxidative effect (total phenolic content, DPPH radical scavenging activity, $\mathrm{ABTS}^{+}$reducing activity, reducing power, and TBARS value) in the thigh from the broilers improved significantly with $1.0 \%$ GL. Linoleic acid and docosahexaenoic acids were higher in the broilers fed both levels of dietary GL. However, volatile basic nitrogen content and microbiological quality was not shown to be different between control and treated group. Results indicate that $1.0 \%$ dietary supplementation of GL can improve the antioxidant activity of broiler thigh meat and may enhance the meat quality. (Key Words: Broiler, Thigh Meat, Gallic Acid, Linoleic Acid, Quality)
\end{abstract}

\section{INTRODUCTION}

Recently, there has been an increasing preference for foods that gratify palatability, nutrition, and physiologic functions to prevent aging and chronic diseases. Various studies are being made of functional foods and ingredients in academic and industrial circles (Kwon et al., 2010). As the frequency of dine-out has increased all over the world, the consumption of fast foods and convenient meat products has increased rapidly, which implies a need for the production of functional fresh meat (Zhang et al., 2010).

Polyunsaturated fatty acids (PUFAs) are considered as functional ingredients to prevent coronary heart diseases and other chronic diseases (Russo, 2009; Krauss et al., 2001). In particular, linoleic acid (LA; $\left.\mathrm{C}_{18: 2 n-6}\right)$ is one of the essential fatty acid and the primary precursor of all $n-6$ PUFAs (Russo, 2009). Also, it is a principal component of phospholipid that forms cell membrane and, at the same

\footnotetext{
* Corresponding Author: Cheorun Jo. Tel: +82-42-821-5774, ax: +82-42-825-9754, E-mail: cheorun@cnu.ac.kr

${ }^{1}$ Department of Animal Science and Biotechnology, Chungnam National University, Daejeon 305-764, Korea.

2 Department of Animal Resources Technology, Gyungnam National University of Science and Technology, Jinju, 660-758, Korea.

Submitted May 11, 2012; Accepted Aug. 15, 2012; Revised Sept. 6, 2012
}

time, is a very important nutrient. It is converted into prostaglandin, a hormone that keeps tissues and cells steady-state, via fatty acids such as $\gamma$-linolenic acid, dihomo- $\gamma$-linolenic acid, and arachidonic acid in the human body. For this reason, several studies had been conducted to increase the content in PUFAs in chickens and eggs by using dietary fat sources such as natural oil containing PUFAs and LA (Crespo and Esteve-Garcia, 2002; Kim et al; 2007).

However, PUFAs are prone to oxidation since they are the first targets for free radical strike at initiating peroxidation (Scislowski et al., 2005). Thus, PUFA-bearing foods cause lipid oxidation and as a result bring on off-odor, discoloration, textural change and nutritional deterioration. The intake of oxidized foods may cause damage to internal organs (Mielnik et al., 2006; Priscilla and Prince, 2009).

Accordingly, natural or synthetic antioxidants are used to minimize the oxidation of dietary lipid. Currently, the interest in natural antioxidants has increased because they are considered to be safer than the synthetic antioxidant, and have greater application potential for consumers' acceptability, palatability, stability, and shelf-life of meat products (Kang et al., 2008; Naveena et al., 2008; Park and Kim, 2008).

Gallic acid (GA), representative natural antioxidants, is 
found in persimmon, wine, and herbs (Kim et al., 2006; Hogan et al., 2009). GA, a metabolite of propyl gallate, is known to possess several pharmacological and biological activities such as strong antioxidant, anti-carcinogenic, antimutagenic, anti-allergic, and anti-inflammatory (Schlesier at al., 2002; Jo et al., 2006). Some studies reported that synthesized GA-LA had a strong biological activities, such as antioxidant, tyrosinase inhibition effect, and synergistic inhibition effect on cancer cell proliferation (in vitro) (Jo et al., 2006; Jang et al., 2008b). In our previous study, Jung et al. (2010) indicated that the breast meat had been superior in antioxidant potential and functionality when GA and LA were added at $1 \%$ level in broiler's diet. Recently, Jung et al. (2011) reported that dietary supplementation of GA and LA mixture or their synthetic salt on layers increased PUFAs and decreased cholesterol level in egg yolk.

The objective of this study was to investigate the physical and chemical properties, antioxidant activity, fatty acid composition and microbial population in the thigh meat of broilers when they were fed the combination of GA and LA in the diet.

\section{MATERIALS AND METHODS}

\section{Animal and experimental design}

A total of $90 \mathrm{~d}$ old chick male and female broilers (Ross strain) were obtained from a commercial hatchery. Broilers were randomly assigned to 9 pens under the standard condition of temperature, humidity, and ventilation, and 24 $\mathrm{h}$ fluorescent lighting for the entire experimental period. Broilers had ad libitum accessed to water and diet, and were fed a commercial broiler starter ( 0 to $6 \mathrm{~d}$ ) and grower ( 7 to $21 \mathrm{~d})$ diets. At the end of the wk 3, broilers were weighed and reassigned to 3 different dietary treatments based on the average weight. During the 22 to $36 \mathrm{~d}$ of the experimental period broilers were fed the following diets: i) The control diet (commercial finisher diet) contained approximately $20 \%$ of crude protein, $4 \%$ of crude fiber, 3,100 ME kcal $/ \mathrm{kg}$ and was a typical commercial diet produced for broilers (Chunhajeil Feed Co., Daejeon, Korea), ii) 0.5\% GL (w/w, GA:LA = $1 \mathrm{M}: 1 \mathrm{M}$, equal molar ratio)+control, and iii) $1.0 \%$ GL+control. GA and LA were purchased from Yakuri Chemical Co. (Osaka, Japan) and Sigma-Aldrich Co. (St. Louis, MO, USA), respectively. Each treatment had three pens, each pen contained 10 broilers. At the end of the experimental period, d 36, 7 broilers from each pen were slaughtered in the research unit by the carotid amputation. The carcasses were removed of feathers, eviscerated, vacuum packed and were stored in a deep freezer at $-50^{\circ} \mathrm{C}$ until required for analysis.

Broilers care facilities and the procedures performed met or exceeded the standards established by the Committee for Accreditation of Laboratory Animal Care at Chungnam
National University, Korea. The study was conducted in accordance with recommendations described in "The Guide for the Care and Use of Laboratory Animals" published by the institutional Animal Care and Use Committee (IACUC) of Chungnam National University.

\section{Broiler meat quality}

The frozen broiler carcasses were thawed in a refrigerated condition $\left(4^{\circ} \mathrm{C}\right)$ for $48 \mathrm{~h}$. The thigh meat was collected from leg meat except for drum-stick.

pH

Sample (1 g) and $9 \mathrm{ml}$ of deionized distilled water (DDW) were homogenized for $15 \mathrm{~s}$ using homogenizer (T25b, Ika Works (Asia), Sdn, Bhd, Malaysia). After filtration using filter paper (No. 4, Whatman Ltd., Kent, $\mathrm{UK}$ ), $\mathrm{pH}$ were measured using a $\mathrm{pH}$ meter (SevenGo, Mettler-Toledo Int. Inc., Schwerzenbach, Switzerland).

\section{Water holding capacity}

Water holding capacity of thigh meat of broiler was measured by the method of Jung et al. (2010). One gram of the minced thigh meat of broiler was placed on a round filter paper (No.4, Whatman Ltd. Kent, UK). The filter paper with meat was placed into centrifuge tube and the tube was centrifuged (CR 20B2, Hitachi Koki Co., Ltd. Fukuoka, Japan) at $6,710 \times \mathrm{g}$ for $10 \mathrm{~min}$. The released water absorbed into the filter paper was weighed and calculated as a percentage of the initial moisture of meat.

\section{Measurement of antioxidant potential}

The meat sample was treated following the method described by Jung et al. (2010) for measurement of antioxidant potential. Thigh meat of broiler $(3 \mathrm{~g})$ were homogenized (T25b, Ika Works (Asia)., Sdn, Bhd, Malaysia) in $15 \mathrm{ml}$ of $\mathrm{DDW}$ at $1,130 \times \mathrm{g}$ for $1 \mathrm{~min}$. Chloroform $(10 \mathrm{ml})$ was added to the homogenates and the mixture was shaken vigorously 2 to 3 times. Lipids and the aqueous supernatant were separated by centrifugation (Union 32R, Hanil Co., Ltd., Inchun, Korea) at 2,090×g for $15 \mathrm{~min}$. After removing lipid layer, The supernatant was used for the measurement of total phenolic content, 1,1diphenyl-2-picrylhydrazyl (DPPH) radical scavenging activity, 2,2-azinobis-(3 ethylbenzothiazoline-6-sulfonic acid) $\left(\mathrm{ABTS}^{+}\right)$reducing activity and reducing power.

\section{Total phenolic content}

Total phenolic content was estimated by the FolinCiocalteu method (Subramanian et al., 1965). A $0.1 \mathrm{ml}$ aliquot was added to the Folin-Ciocalteu reagent $(0.2 \mathrm{ml})$, followed by the addition of $3 \mathrm{ml}$ sodium carbonate solution $(5 \%)$. The reaction mixture was vortexed and the absorbance was measured with a UV/VIS 
spectrophotometer (DU 530, Beckman Instruments Inc., Fullerton, CA, USA) at $765 \mathrm{~nm}$ after incubation for $1 \mathrm{~h}$ at $23^{\circ} \mathrm{C}$. The quantification of phenolics was based on the standard curve generated with the use of gallic acid, and expressed as gallic acid equivalent.

\section{DPPH radical scavenging activity}

DPPH radical scavenging activity was estimated according to the method of Blois (1958) with slight modifications. A $200 \mu \mathrm{l}$ aliquot was added to $800 \mu \mathrm{lDDW}$ and $1 \mathrm{ml}$ methanolic DPPH solution $(0.2 \mathrm{mM})$. The mixture was vortexed and left to stand at room temperature (20 to $22^{\circ} \mathrm{C}$ ) for $30 \mathrm{~min}$. A tube containing $1 \mathrm{ml}$ of DDW and $1 \mathrm{ml}$ of methanolic DPPH solution $(0.2 \mathrm{mM})$ served as the control. The absorbance of the solution was measured at 517 nm using a UV/VIS spectrophotometer (DU 530, Beckman Instruments Inc., Fullerton, CA, USA). The percentage of DPPH radical scavenging was obtained from the following equation:

DPPH radical scavenging activity $(\%)$

$=\left(1-\left(\mathrm{A}_{1} / \mathrm{A}_{0}\right)\right) \times 100$

Where $A_{0}$ is the absorbance of the blank and $A_{1}$ is the absorbance of the sample.

\section{$\mathrm{ABTS}^{+}$reducing activity}

$\mathrm{ABTS}^{+}$reducing activity was determined as the method described by Erel (2004). ABTS was dissolved in distilled water to a $7 \mathrm{mM}$ concentration. The ABTS radical cation was produced by acting the ABTS stock solution with 2.45 $\mathrm{mM}$ potassium persulfate (final concentration) in the dark at room temperature for 12 to $16 \mathrm{~h}$ to allow the completion of radical generation. This solution was then diluted with ethanol so that its absorbance was adjusted to $0.70 \pm 0.02$ at $734 \mathrm{~nm}$. The diluted $\mathrm{ABTS}^{+}$solution $(3 \mathrm{ml})$ were added to $20 \mu \mathrm{l}$ aqueous supernatant and the absorbance was measured by a UV/VIS spectrophotometer (DU 530, Beckman Instruments Inc., Fullerton, CA, USA) at $734 \mathrm{~nm}$ using ethanol as a blank. The percentage inhibition was calculated by the following equation:

$$
\mathrm{ABTS}^{+} \text {reducing activity }(\%)=\left(\left(\mathrm{A}_{0}-\mathrm{A}_{1}\right) / \mathrm{A}_{0}\right) \times 100
$$

Where $A_{0}$ is the absorbance of the control and $A_{1}$ is the absorbance of the sample.

\section{Reducing power}

The reducing power was determined according to the method of Oyaizu (1986). A $200 \mu \mathrm{l}$ aliquot was mixed with $500 \mu \mathrm{l}$ sodium phosphate buffer $(0.2 \mathrm{M}, \mathrm{pH}$ 6.6) and $500 \mu \mathrm{l}$ potassium ferricyanide $(1 \%)$, and the resultant mixture was incubated at $50^{\circ} \mathrm{C}$ for $20 \mathrm{~min}$. After addition of $2.5 \mathrm{ml}$ trichloroacetic acid (TCA, (10\%)), the mixture was centrifuged (Union 32R, Hanil Co., Ltd., Inchun, Korea) at $2,200 \times \mathrm{g}$ for $10 \mathrm{~min}$. The upper layer $(500 \mu \mathrm{l})$ was mixed with $500 \mu \mathrm{l}$ distilled water and $100 \mu \mathrm{l}$ ferric chloride $(0.1 \%)$, and the absorbance was measured at $700 \mathrm{~nm}$ using a spectrophotometer (DU 530, Beckman Instruments Inc., Fullerton, CA, USA): higher absorbance indicates higher reducing power.

\section{2-Thiobarbituric acid-reactive substances (TBARS) value}

Each meat sample (5 g) in $15 \mathrm{ml}$ DDW was homogenized (Ika Works) at $1,130 \times \mathrm{g}$ for $1 \mathrm{~min}$. Sample homogenate $(1 \mathrm{ml})$ was transferred to a test tube and lipid oxidation was determined as the TBARS value by using the method described by Ahn et al. (1999). Briefly, $50 \mu \mathrm{l}$ butylated hydroxyanisol (7.2\%) and $2 \mathrm{ml}$ TBA/TCA solution (20 mM TBA in $15 \%$ TCA) were added to the test tube. Tubes were heated $\left(90^{\circ} \mathrm{C}\right)$ in a boiling water bath for $30 \mathrm{~min}$, cooled, and then centrifuged (Union 32R, Hanil Co., Ltd., Inchun, Korea) at 2,090 $\times$ g for $15 \mathrm{~min}$. Absorbance of the supernatant was measured at $532 \mathrm{~nm}$ with a UV/VIS spectrophotometer (DU 530, Beckman Instruments Inc., Fullerton, CA, USA). TBARS value was reported as mg malondialdehyde per $\mathrm{kg}$ meat.

\section{Fatty acid composition}

Total lipid of thigh meat was extracted by using chloroform-methanol $(2: 1, \mathrm{v} / \mathrm{v})$ according to the procedure of Folch et al. (1957). The fatty acid methyl esters were prepared from the extracted lipids with $\mathrm{BF}_{3}$-methanol (Sigma-Aldrich). The fatty acid methyl esters were, then, separated on a gas chromatograph (Agillent GC 6890N, Palo Alto, CA, USA) equipped with a mass selective detector (MSD). A split inlet (split ratio, 50:1) was used to inject samples into a HP-5MS capillary column (30 $\mathrm{m} \times 0.25$ $\mathrm{mm} \times 0.25 \mu \mathrm{m})$, and ramped oven temperature was used $\left(150^{\circ} \mathrm{C}\right.$ for $3 \mathrm{~min}$, increased to $180^{\circ} \mathrm{C}$ at $2.5^{\circ} \mathrm{C} / \mathrm{min}$ and maintained for $5 \mathrm{~min}$, then increased to $220^{\circ} \mathrm{C}$ at $2.5^{\circ} \mathrm{C} / \mathrm{min}$ and maintained for $25 \mathrm{~min}$ ). Inlet temperature was $210^{\circ} \mathrm{C}$. Helium was the carrier gas at constant flow of $0.7 \mathrm{ml} / \mathrm{min}$. The temperature of the mass spectrometer (MS) source, MS quadrupole, and the transfer line into the MS were 230, 150, and $280^{\circ} \mathrm{C}$ respectively. The fatty acid composition was identified by a mass spectrum database (NIST Library, mass spectral search program, version 5.0, Ringoes, NJ, USA).

\section{Volatile basic nitrogen (VBN)}

Measurement of VBN in the thigh meat of broiler was done according to Conway (1950). Each meat sample (3 g) was homogenized for $1 \mathrm{~min}$ with $3 \mathrm{ml}$ distilled water and 6 $\mathrm{ml}$ TCA (10\%), and then centrifuged (Union 32R, Hanil Co., Ltd., Inchun, Korea) at 2,090 $\times$ g for $15 \mathrm{~min}$. The supernatant was filtered using a filter paper (No. 4, Whatman), and the 
filtrate was placed in a test tube and made up to a final volume of $30 \mathrm{ml}$ with $5 \%$ TCA. A $1 \mathrm{ml}$ of $0.01 \mathrm{~N}$ boric acid as a VBN absorber was placed in the inner section of a Conway micro-diffusion cell (Sibata Ltd. Tokyo, Japan). A $1 \mathrm{ml}$ sample solution and $1 \mathrm{ml}$ saturated $\mathrm{K}_{2} \mathrm{CO}_{3}$ was also placed into the outer section of the same cell and the lid was immediately closed. A 5\% TCA solution was used as blank. The cell was incubated at $37^{\circ} \mathrm{C}$ for $120 \mathrm{~min}$, and then titrated against $0.02 \mathrm{~N}$ sulfuric acid. The concentration of VBN was calculated as ammonia equivalent using the following equation:

\author{
VBN value (mg \%) \\ $=(0.28 \times($ titration volume of sample solution \\ -titration volume of blank) $\times 10) \times 100$
}

\section{Microbiological analysis}

Media for the enumeration of the total aerobic bacteria were prepared by tryptic soy agar (Difco Laboratories, Detroit, MI, US; PCA) to provide the optimum conditions for the growth of halophiles. The thigh meat $(10 \mathrm{~g})$ with 90 $\mathrm{ml}$ saline solution $(0.85 \%, \mathrm{NaCl})$ was homogenized for 2 min using a stomacher homogenizer (BagMixer 400, Interscience, Paris, France) and the homogenate was serially diluted 10-fold with saline solution. Each diluent $(100 \mu \mathrm{l})$ was spread in triplicate on each agar plate and the plate was incubated at $37^{\circ} \mathrm{C}$ for $24 \mathrm{~h}$. Colony forming units (CFU) per gram were counted, at a dilution giving 30 to 300 CFU per plate.

\section{Statistical analysis}

A total 9 pens with 7 broilers per each pen were used for this experiment with 3 replications for each treatment. Analysis of variance was performed using the raw data, and the mean values and standard errors of the means (SEM) were calculated by the Statistical Analysis System (SAS, 2000). Differences among the means were determined by the Duncan's multiple range test with a significance defined at $5 \%$ level.

\section{RESULTS AND DISCUSSIONS}

\section{pH and water holding capacity (WHC)}

The ultimate $\mathrm{pH}$ of postmortem muscle is very important due to the positive correlation with WHC during the conversion of muscle to meat (Bee et al., 2007). Table 1 shows $\mathrm{pH}$ and WHC of the thigh meat from the broiler fed the dietary GL. The results showed that $\mathrm{pH}$ became significantly higher in thigh meat from the broiler fed the $1.0 \%$ dietary GL compared to those of both control and $0.5 \%$ dietary GL treatment (Table 1). It indicated that the $\mathrm{pH}$ decline of thigh meat postmortem was reduced by $1.0 \%$ dietary GL. Jang et al. (2008a) reported that the $\mathrm{pH}$ of
Table 1. $\mathrm{pH}$, water holding capacity (\%), and total phenolic contents (mg gallic acid equivalent/g meat) of the thigh meat from the broilers fed the combination of gallic and linoleic acid

\begin{tabular}{lccc}
\hline Treatment & $\mathrm{pH}$ & $\begin{array}{c}\text { Water holding } \\
\text { capacity }\end{array}$ & Total phenolics \\
\hline Control & $6.11^{\mathrm{y}}$ & $59.19^{\mathrm{y}}$ & $1.00^{\mathrm{y}}$ \\
$0.5 \%$ & $6.14^{\mathrm{xy}}$ & $60.09^{\mathrm{y}}$ & $1.12^{\mathrm{x}}$ \\
$1 \%$ & $6.36^{\mathrm{x}}$ & $65.85^{\mathrm{x}}$ & $1.15^{\mathrm{x}}$ \\
$\mathrm{SEM}^{1}$ & 0.067 & 1.036 & 0.02 \\
\hline
\end{tabular}

${ }^{1}$ Standard errors of mean $(n=9)$.

${ }^{\mathrm{x}, \mathrm{y}}$ Different letters within the same column differ significantly $(\mathrm{p}<0.05)$.

breast meat from broilers fed medicinal herb extract mix was higher than that of control. Olivo et al. (2001) suggested that the occurrence of PSE chicken could be suppressed with reduction of $\mathrm{pH}$ decline at postmortem by dietary antioxidant. This result may be related to the increase of phenolic content in thigh meat from the broiler fed the $1.0 \%$ dietary GL (Table 1). Similarly, WHC of the thigh meat from broilers were significantly increased by the $1.0 \%$ dietary GL treatment when compared with control and $0.5 \%$ dietary GL treatment. Huff-Lonergan and Lonergan (2005) reported that WHC is not only influenced by the $\mathrm{pH}$ but also postmortem proteolysis which begun with the activation $\mu$-calpain, that may inactivated by oxidation. Previous studies have indicated that antioxidants in meat can affect the proteolysis (Rowe et al., 2004).

\section{Antioxidant potential}

Antioxidant potential is the basic physiological role of functional foods. Highly reactive free radicals in biological systems may oxidize nucleic acids, proteins or lipids, and can initiate degenerative disease. To reduce the incidence of chronic disease, including heart disease and some cancers, the antioxidant potential is the main factor underlying efficacy of the foods (Choi et al., 2011). Several analyses were conducted to evaluate antioxidant potential (Table 2) and total phenolic content (Table 1) of the thigh meat fed GL.

Total phenolic content indicated $1.00 \mathrm{mg}$ gallic acid equivalent/g of thigh meat in the control group. In dietary GL group, however, it indicated 1.12 to $1.15 \mathrm{mg}$ gallic acid equivalnt/g (Table 1). Thus, total phenolic content was higher in the thigh meat fed GL than that in the control. Jung et al. (2010) also found that dietary GA with LA increased the total phenolic content of breast meat from broiler since GA is a natural polyphenol (Kim et al., 2006). Previous studies reported that total phenolic contents in breast and thigh meat of broilers fed medicinal herb extract mix containing polyphenols were higher than those of control (Jang et al., 2008a; Jo et al., 2009), which is consistent with the present study. Nagendra Prasad et al. (2009) suggested that polyphenol content showed high correlation with total antioxidant capacity $\left(\mathrm{R}^{2}=0.98\right)$. 
Table 2. Antioxidative activities of the thigh meat from the broilers fed the combination of gallic and linoleic acid during storage at $4{ }^{\circ} \mathrm{C}$

\begin{tabular}{|c|c|c|c|c|c|}
\hline \multirow{2}{*}{ Treatment } & \multicolumn{4}{|c|}{ Storage $(\mathrm{d})$} & \multirow{2}{*}{$\mathrm{SEM}^{1}$} \\
\hline & 0 & 2 & 4 & 7 & \\
\hline \multicolumn{6}{|c|}{ DPPH radical scavenging activity $(\%)$} \\
\hline Control & $57.61^{\text {ay }}$ & $50.30^{\text {by }}$ & $39.97^{\text {cy }}$ & $37.70^{\mathrm{dy}}$ & 0.492 \\
\hline $0.5 \%$ & $66.28^{\mathrm{ax}}$ & $62.00^{\mathrm{ax}}$ & $53.32^{\mathrm{bx}}$ & $47.00^{\mathrm{cx}}$ & 1.441 \\
\hline $1.0 \%$ & $64.30^{\mathrm{axy}}$ & $59.03^{\text {bx }}$ & $55.72^{\mathrm{cx}}$ & $48.04^{\mathrm{cx}}$ & 0.733 \\
\hline SEM $^{2}$ & 0.563 & 0.861 & 0.754 & 1.477 & \\
\hline \multicolumn{6}{|c|}{$\mathrm{ABTS}^{+}$reducing activity $(\%)$} \\
\hline Control & $30.22^{\text {ay }}$ & $27.31^{\text {by }}$ & $22.88^{\mathrm{cz}}$ & $23.83^{\text {cy }}$ & 0.843 \\
\hline $0.5 \%$ & $37.86^{\mathrm{ax}}$ & $36.39^{\mathrm{ax}}$ & $30.82^{\text {by }}$ & $31.28^{\mathrm{bx}}$ & 1.339 \\
\hline $1.0 \%$ & $36.07^{\mathrm{abx}}$ & $37.02^{\mathrm{ax}}$ & $34.04^{\mathrm{abx}}$ & $33.23^{b x}$ & 1.059 \\
\hline SEM $^{2}$ & 0.967 & 1.409 & 0.782 & 1.142 & \\
\hline \multicolumn{6}{|c|}{ Reducing power } \\
\hline Control & $0.466^{\text {ay }}$ & $0.443^{\mathrm{bz}}$ & $0.351^{\mathrm{cy}}$ & $0.290^{\mathrm{dy}}$ & 0.0052 \\
\hline $0.5 \%$ & $0.544^{\mathrm{ax}}$ & $0.530^{\mathrm{ax}}$ & $0.441^{\mathrm{bx}}$ & $0.401^{\mathrm{bx}}$ & 0.0127 \\
\hline $1.0 \%$ & $0.491^{\text {ay }}$ & $0.466^{\text {by }}$ & $0.440^{\mathrm{cx}}$ & $0.378^{\mathrm{dx}}$ & 0.0048 \\
\hline SEM $^{2}$ & 0.0085 & 0.0061 & 0.0070 & 0.0110 & \\
\hline \multicolumn{6}{|c|}{ TBARS value } \\
\hline Control & $0.44^{\mathrm{cx}}$ & $0.53^{\mathrm{b}}$ & $0.67^{\mathrm{ax}}$ & $0.70^{\mathrm{ax}}$ & 0.024 \\
\hline $0.5 \%$ & $0.47^{\mathrm{cx}}$ & $0.54^{\mathrm{b}}$ & $0.55^{\text {by }}$ & $0.64^{\text {ay }}$ & 0.011 \\
\hline $1.0 \%$ & $0.29^{\text {by }}$ & $0.54^{\mathrm{a}}$ & $0.59^{\mathrm{ay}}$ & $0.61^{\mathrm{az}}$ & 0.021 \\
\hline SEM $^{2}$ & 0.013 & 0.030 & 0.020 & 0.007 & \\
\hline
\end{tabular}

${ }^{1}$ Standard errors of mean $(n=12) \cdot{ }^{2} n=9$.

${ }^{a-d}$ Different letters within same row differ significantly $(\mathrm{p}<0.05) .{ }^{\mathrm{x}-\mathrm{z}}$ Different letters within same column differ significantly $(\mathrm{p}<0.05)$.

DPPH is a widely used method for estimating the antioxidant activity. A solution of DPPH, stable free radical, is mixed with an antioxidant that can donate a hydrogen atom to form a stable DPPH-H molecule. Then this reduced form is visualized by the loss of violet color (Molyneux, 2004). The DPPH radical scavenging activity of the thigh meat from broilers fed $0.5 \%$ and $1.0 \%$ dietary GL was significantly higher than that of the control. In control, DPPH radical scavenging activity was lowered from $57.61 \%$ to $37.70 \%$ during the storage period. There were the same trend in the thigh meat fed GL but the difference between GL-treated and control was present during storage. In the previous study, the DPPH radical scavenging activity of GA showed 4-folds higher than that of tocopherol (Jang et al., 2009).

The ABTS, which is a stable free radical cation applicable to both lipophilic and hydrophilic antioxidants, has been used to measure total antioxidant activity (Kim and Lee, 2009). The ABTS radical reducing activity of thigh meat from broilers fed $0.5 \%$ and $1.0 \%$ dietary GL were significantly greater than that of the control. The ABTS radical reducing activity, measured during the storage period. However, dietary GL did not show significant differences. Jo et al. (2009) reported that broilers fed medicinal herb extract mix showed higher ABTS radical reducing activity than control.

The changes of reducing power in thigh meat from the broiler fed the dietary GL was shown Table 2. In this assay, the yellow color of the test solution changes to various shades of green and blue, depending on reducing power. The presence of reducers, such as antioxidants, causes the reduction of the $\mathrm{Fe}^{3+} /$ ferricyanide complex to the ferrous form. Therefore, measuring the formation of Perl's Prussian blue at $700 \mathrm{~nm}$ can monitor the $\mathrm{Fe}^{2+}$ concentration (Kim et al., 2008). The reducing power of thigh meat indicated 0.466 and 0.544 in the control and $0.5 \%$ dietary GL, respectively. The $1.0 \%$ dietary GL group showed a higher value than the control, but did not present difference from $0.5 \%$ level. The reducing power decreased during storage as similar to previous antioxidant potential measurements. During the storage period, it was seen that the dietary supplementation of GL promotes antioxidant potential in thigh meat of broilers.

TBARS value was 0.44 in the control group at $\mathrm{d} 0$ and represented 0.70 after $7 \mathrm{~d}$ of storage by lipid oxidation development. However, the TBARS value was lower in the thigh meat from broilers fed dietary GL than that form control; especially, $1.0 \%$ dietary GL showed the lowest value. The thigh meat from the broilers fed GL produced lower TBARS in spite of the higher content of LA in GL diet. The LA belongs to the PUFA family that has potential to generate several types of free radicals and can accelerate lipid oxidation (Jung et al., 2010). GA in GL diet may also play a role of antioxidant. These results agreed with the 
Table 3. Fatty acid composition in the thigh meat from the broilers the combination of gallic and linoleic acid

\begin{tabular}{lcccc}
\hline Fatty acids & \multicolumn{2}{c}{ Treatment } & SEM $^{1}$ \\
\cline { 2 - 4 } C16:0 & Control & $0.5 \%$ & $1.0 \%$ & 0.125 \\
C16:1 & $22.25^{\mathrm{a}}$ & $22.05^{\mathrm{ab}}$ & $21.57^{\mathrm{b}}$ & 0.132 \\
C18:0 & 3.06 & 2.63 & 3.05 & 0.282 \\
C18:1 & 16.15 & 16.18 & 15.88 & 0.567 \\
C18:2 & 31.29 & 30.39 & 29.86 & 0.179 \\
C18:3 & $17.72^{\mathrm{b}}$ & $18.22^{\mathrm{ab}}$ & $19.01^{\mathrm{a}}$ & 0.021 \\
C20:4 & 0.46 & 0.42 & 0.49 & 0.247 \\
C22:6 & 7.82 & 8.57 & 8.88 & 0.059 \\
Saturated & $1.23^{\mathrm{b}}$ & $1.52^{\mathrm{a}}$ & $1.34^{\mathrm{ab}}$ & 0.193 \\
Monounsaturated & $38.40^{\mathrm{a}}$ & $38.23^{\mathrm{ab}}$ & $37.46^{\mathrm{b}}$ & 0.643 \\
Polyunsaturated & 34.36 & 33.03 & 32.85 & $29.69^{\mathrm{a}}$ \\
Unsaturated:saturated & $27.24^{\mathrm{b}}$ & $28.73^{\mathrm{ab}}$ & $1.67^{\mathrm{a}}$ & 0.488 \\
n-6:n-3 & $1.60^{\mathrm{b}}$ & $1.61^{\mathrm{b}}$ & 15.15 & 0.010 \\
\hline
\end{tabular}

${ }^{1}$ Standard errors of mean $(\mathrm{n}=9) .{ }^{\mathrm{a}-\mathrm{b}}$ Different letters within same row differ significantly $(\mathrm{p}<0.05)$.

other studies which showed that lipid oxidation of the meat from the chickens fed various PUFA levels with $\alpha$ tocopheryl acetate was inhibited due to the antioxidant activity of $\alpha$-tocopheryl acetate (Cortinas et al., 2005).

The results showed that dietary GL increased the antioxidant potential by increase of total phenolic content of thigh meat. These results agreed with previous study, which showed that antioxidant potential of breast meat from broiler was increased by dietary GA with LA (Jung et al., 2010). In addition, other dietary phenolic source such as oregano, rosemary, sage essential oil, and grape pomace had significant antioxidative activities in lamb and broiler meat (Goñi et al., 2007; Simitzis et al., 2008).

\section{Fatty acid composition}

Table 3 show the influence of dietary GL on fatty acid composition in the thigh meat of broilers. Previous studies have described how the fatty acid composition of chicken meat depends on the fatty acid profile of the feed (Cherian et al., 1996; Bou et al., 2004). The palmitic acid (C16:0) was higher in the control group than in GL diet groups. The saturated fatty acid (SFA) content was lower in GL diet groups, and became lower in inverse proportion to the GL content. SFAs in poultry tissues rely upon their presence in the diet and their synthesis in the liver. The SFAs synthesis is inhibited in the liver more during digestion of unsaturated fats than saturated fats (Sim and Qi, 1995). On the other hand, linoleic acid (LA, $\mathrm{C}_{18: 2 \mathrm{n}-6}$ ) and docosahexaenoic acid (DHA, $\mathrm{C}_{22: 6 n-3}$ ), PUFAs, were higher in GL diet groups. The high LA content in thigh meat from GL diet groups was associated with the levels of LA in diet. Zelenka et al. (2008) reported that LA contents of breast and leg meat from broilers fed linseed cultivar Lola with a high content of LA were increased in a concentration dependent manner. Also, dietary sunflower oil containing high LA increased
LA deposition in broiler (Crespo and Esteve-Garcia, 2002). The antioxidant could influence fatty acid content of meat by preventing oxidation of PUFAs (Jahan et al., 2005). Therefore, the increased of antioxidant potential in thigh meat from GL diet groups may be related to high DHA content in thigh meat from GL diet groups. The PUFAs/SFAs ratio in the thigh meat from broilers was increased by $1.0 \%$ dietary GL supplementation. These results can be attractive to the consumers as high PUFAs/SFAs ratio has a positive health benefit for humans, mainly in protection against cardiovascular disease (Krauss et al., 2001).

\section{Volatile basic nitrogen (VBN)}

Table 4 shows the VBN content in the thighs meat of broilers that were fed dietary GL. The VBN content increased in proportion to the storage period not only in the control group but in dietary GL groups. The three groups did not show significant differences throughout the storage period. The VBN content has been considered as spoilage indicator, and is increased by proteolysis carried out by microorganisms and enzymes in meat (Kruk et al., 2011). Thus, the supply of dietary GL may not be correlated with antibacterial activity in thigh meat. Jung et al. (2010) showed that the VBN content in the breast meat from the

Table 4. Volatile basic nitrogen ( $\mathrm{mg} \%)$ in the thigh meat from the broilers fed combination of gallic and linoleic acid

\begin{tabular}{lccccc}
\hline \multirow{2}{*}{ Treatment } & \multicolumn{4}{c}{ Storage (d) } & \multirow{2}{*}{ SEM $^{1}$} \\
\cline { 2 - 5 } & 0 & 2 & 4 & 7 & \\
\hline Control & $12.1^{\mathrm{cb}}$ & $11.2^{\mathrm{c}}$ & $14.0^{\mathrm{b}}$ & $17.7^{\mathrm{a}}$ & 0.66 \\
$0.5 \%$ & $12.6^{\mathrm{cb}}$ & $11.2^{\mathrm{c}}$ & $14.0^{\mathrm{b}}$ & $17.7^{\mathrm{a}}$ & 0.62 \\
$1.0 \%$ & $13.1^{\mathrm{b}}$ & $11.2^{\mathrm{c}}$ & $14.0^{\mathrm{b}}$ & $16.8^{\mathrm{a}}$ & 0.47 \\
$\mathrm{SEM}^{2}$ & 0.89 & 0.00 & 0.00 & 0.76 & \\
\hline
\end{tabular}

${ }^{1}$ Standard errors of mean $(n=12) .{ }^{2} n=9$.

${ }^{\mathrm{a}-\mathrm{c}}$ Different letters within same row differ significantly $(\mathrm{p}<0.05)$. 
Table 5. Number of total aerobic bacteria $(\log \mathrm{CFU} / \mathrm{g})$ in the thigh meat from the broilers fed combination of gallic and linoleic acid

\begin{tabular}{lccccc}
\hline \multirow{2}{*}{ Treatment } & \multicolumn{4}{c}{ Storage (d) } & \multirow{2}{*}{ SEM $^{1}$} \\
\cline { 2 - 5 } & 0 & 2 & 4 & 7 & \\
\hline Control & $3.95^{\mathrm{c}}$ & $3.85^{\mathrm{c}}$ & $4.26^{\mathrm{bx}}$ & $5.49^{\mathrm{ax}}$ & 0.061 \\
$0.5 \%$ & $3.51^{\mathrm{c}}$ & $3.74^{\mathrm{b}}$ & $3.93^{\mathrm{by}}$ & $5.20^{\mathrm{az}}$ & 0.048 \\
$1.0 \%$ & $3.36^{\mathrm{c}}$ & $3.78^{\mathrm{bc}}$ & $4.21^{\mathrm{bx}}$ & $5.39^{\mathrm{ay}}$ & 0.113 \\
$\mathrm{SEM}^{2}$ & 0.143 & 0.037 & 0.053 & 0.010 & \\
\hline
\end{tabular}

${ }^{1}$ Standard errors of mean $(n=12) .{ }^{2} n=9$

${ }^{a-c}$ Different letters within same row differ significantly $(p<0.05)$

${ }^{x-z}$ Different letters within same column differ significantly $(\mathrm{p}<0.05)$.

broilers fed $1.0 \%$ mixture of GA and LA was lower than that of control at storage $\mathrm{d} 7$ (16.80 vs $19.60 \mathrm{mg} \%)$. The authors suggest that the shelf-life of the breast meat from broilers may be improved slightly by $1.0 \%$.

\section{Microbial analysis}

Microbial population of the thigh meat was $3.95 \mathrm{log}$ $\mathrm{CFU} / \mathrm{g}$ initially, but increased in proportion to the storage period regardless of treatments (Table 5). In the thigh meat from broilers fed $0.5 \%$ dietary GL, the rate of increase decreased significantly from $\mathrm{d} 4$, however, that fed $1.0 \%$ did not. In further storage, the difference was found at $\mathrm{d} 7$. Further study in antimicrobial effect of dietary supplementation of GL is needed in this regard since GL diet consisted of LA and GA which are known to possess antimicrobial activity (Rodriguez-Vaquero et al., 2007). Jung et al. (2010) investigated that the storage stability of breast meat in broilers that were fed mixture of GA and LA, and reported that microbial population significantly decreased from the $\mathrm{d} 4$ when $1.0 \%$ was supplemented.

In conclusion, dietary GL at $1 \%$ level increased functionality of thigh meat by increase of WHC. The antioxidant potential of the thigh meat was improved by dietary GL. The dietary GL at $1 \%$ level may achieve high nutritional value of thigh meat of broilers by increase of essential fatty acid, LA, and DHA. Therefore, the dietary GL at $1 \%$ level can improve the quality of thigh meat from broilers.

\section{ACKNOWLEDGMENTS}

This work was supported by a grant from the NextGeneration BioGreen 21 Program (No. PJ0081330), Rural Development Administration, Republic of Korea.

\section{REFERENCES}

Ahn, D. U., D. G. Olson, C. Jo, J. Love and S. K. Jin. 1999. Volatiles production and lipid oxidation on irradiated cooked sausage as related to packaging and storage. J. Food Sci. 64: 226-229.

Bee, G., A. L. Anderson, S. M. Lonergan and E. Huff-Lonergan.
2007. Rate and extent of $\mathrm{pH}$ decline affect proteolysis of cytoskeletal proteins and water-holding capacity in pork. Meat Sci. 76:359-365.

Blois, M. S. 1958. Antioxidant determination by the use of a stable free radical. Nature 181:1199-1200.

Bou, R., F. Guardiola, A. Tres, A. C. Barroeta and R. Codony. 2004. Effect of dietary fish oil, $\alpha$-tocopheryl acetate, and zinc supplementation on the composition and consumer acceptability of chicken meat. Poult. Sci. 83:282-292.

Cherian, G., F. W. Wolfe and J. S. Sim. 1996. Dietary oils with added tocopherols: Effects on egg or tissue tocopherols, fatty acids, and oxidative stability. Poult. Sci. 75:423-431.

Choi, J., H. J. Kim and J. W. Lee. 2011. Structural feature and antioxidant activity of low molecular weight laminarin degraded by gamma irradiation. Food Chem. 129:520-523.

Conway, E. J. 1950. Microdiffusion analysis and volumetric error, $3^{\text {rd }}$ ed. London: Crosby Lockwood and Son Ltd.

Cortinas, L., A. Barroeta, C. Villaverde, J. Galobart, F. Guardiola and M. D. Baucells. 2005. Influence of the dietary polyunsaturation level on chicken meat quality: Lipid oxidation. Poult. Sci. 84:48-55.

Crespo, N. and E. Esteve-Garcia. 2002. Nutrient and fatty acid deposition in broiler fed different dietary fatty acid profiles. Poult. Sci. 81:1533-1542.

Erel, O. 2004. A novel automated direct measurement method for total antioxidant capacity using a new generation, more stable ABTS radical cation. Clin. Biochem. 37:277-285.

Folch, J., M. Less and G. H. Sloane Stanley. 1957. A simple method for the isolation and purification of total lipids from animal tissues. J. Biol. Chem. 226:497-509.

Goñi, I., A. Brenes, C. Centeno, A. Viveros, F. Saura-Calixtio, A. Rebole, I. Arija and R. Estevez. 2007. Effect of dietary grape pomace and vitamin $\mathrm{E}$ on growth performance, nutrient digestibility, and susceptibility to meat lipid oxidation in chickens. Poult. Sci. 86:508-516.

Hogan, S., L. Zhang, J. Li, B. Zoecklein and K. Zhou. 2009. Antioxidant properties and bioactive components of Norton (Vitis aestivallis) and Cabernet Franc (Vitis vinifera) wine grapes. LWT-Food Sci. Technol. 42:1269-1274.

Huff-Lonergan, E. and S. M. Lonergan. 2005. Mechanisms of water-holding capacity of meat: The role of postmortem biochemical and structural changes. Meat Sci. 71:194-204.

Jahan, K., A. Paterson, J. Piggott and C. Spickett. 2005. Chemometric modeling to relate antioxidants, neutral lipid fatty acids, and flavor components in chicken breasts. Poult. Sci. 84:158-166.

Jang, A., X. D. Liu, M. H. Shin, B. D. Lee, S. K. Lee, J. H. Lee and C. Jo. 2008a. Antioxidative potential of raw breast meat from broiler chicks fed a dietary medicinal herb extract mix. Poult. Sci. 87: 2382-2389.

Jang, A., P. Srinivasan, N. Y. Lee, H. P. Song, J. W. Lee, M. Lee and C. Jo. 2008b. Comparison of hypolipidemic activity of synthetic gallic acid-linoleic acid ester with mixture of gallic acid and linoleic acid, gallic acid, and linoleic acid on high-fat diet induced obesity in C57BL/6 Cr Slc mice. Chem-Biol. Interact. 174:109-117.

Jang, A., N. Y. Lee, B. D. Lee, T. H. Kim, J. H. Son, B. J. An and C. Jo. 2009. Biological functions of a synthetic compound, octadeca-9,12-dienyl-3,4,5-hydroxybenzoate, from gallic acid- 
linoleic acid ester. Food Chem. 112:369-373.

Jo, C., A. Jang, S. Jung, J. H. Choe, B. Kim and K. H. Lee. 2009. Effect of dietary herb extract mix on antioxidative activity of chicken thigh meat. J. Korean Soc. Food Sci. Nutr. 38:302-308.

Jo, C., I. Y. Jeong, N. Y. Lee, K. S. Kim and M. W. Byun. 2006. Synthesis of a novel compound from gallic acid and linoleic acid and its biological functions. Food Sci. Biotechnol. 15:317-320.

Jung, S., J. H. Choe, B. Kim, H. Yun, Z. A. Kruk and C. Jo. 2010. Effect of dietary mixture of gallic acid and linoleic acid on antioxidative potential and quality of breast meat from broilers. Meat Sci. 86:520-526.

Jung, S., B. H. Han, K. C. Nam, D. U. Ahn, J. H. Lee and C. Jo. 2011. Effect of dietary supplementation of gallic acid and linoleic acid mixture or their synthetic salt on egg quality. Food Chem. 129:822-829.

Kang, H. K., K. H. Kang, J. C. Na, D. J., Yu, D. U. Kim, S. J. Lee and S. H. Kim. 2008. Effects of feeding Rhus verniciflua extracts on egg quality and performance of laying hens. Korean J. Food Sci. An. 28:610-615.

Kim, J. H., J. Hwangbo, N. J. Choi, H. G. Park, D. H. Yoon, E.W. Park and Y. J. Kim. 2007. Effect of dietary supplementation with conjugated linoleic acid, with oleic, linoleic, or linolenic acid, on egg quality characteristics and fat accumulation in the egg yolk. Poult. Sci. 86:1180-1186.

Kim, J. K., P. Srinivasan, J. H. Kim, J. Choi, H. J. Park, M. W. Byun and J. W. Lee. 2008. Structural and antioxidant properties of gamma irradiated hyaluronic acid. Food Chem. 109:763-770.

Kim, J. S. and Y. S. Lee. 2009. Antioxidant activity of maillard reaction products derived from aqueous glucose/glycine, diglycine, and triglycine model systems as a function. Food Chem. 116:227-232.

Kim, S. H., C. D. Jun, K. Suk, B. J. Choi, H. Lim, S. Park, S. H. Lee, H. Y. Shin, D. K. Kim and T. Y. Shin. 2006. Gallic acid inhibits histamine release and pro-inflammatory cytokine production in mast cells. Toxicol. Sci. 91:123-131.

Krauss, R. M., R. Eckel, B. Howard, L. J. Appel, S. R. Daniels, R. J. Deckelbaum et al. 2001. Revision 2000: Statement for healthcare professionals from the nutrition committee of the American Heart Association. J. Nutr. 131:132-146.

Kruk, Z. A., H. Yun, D. L. Rutley, E. J. Lee, Y. J. Kim and C. Jo. 2011. The effect of high pressure on microbial population, meat quality and sensory characteristics of chicken breast fillet. Food Control 22:6-12.

Kwon, S. C., G. H. Choi, J. H. Hwang and K. H. Lee. 2010. Physicochemical property and antioxidative activity of hotwater extracts from enzyme hydrolysate of Astragalus membranaceus. J. Korean Soc. Food Sci. Nutr. 39:406-413.

Mielnik, M. B., E. Olsen, G. Vogt, D. Adeline and G. Skrede. 2006. Grape seed extract as antioxidant in cooked, cold stored turkey meat. LWT-Food Sci. Technol. 39:191-198.

Molyneux, P. 2004. The use of the stable free radical diphenylpicryl-hydrazyl (DPPH) for estimation antioxidant activity. Songklanakarin J. Sci. Technol. 26:211-219.

Nagendra Prasad, K., B. Yang, S. Yang, Y. Chen, M. Zhao, M. Ashraf and Y. Jiang. 2009. Identification of phenolic compounds and appraisal of antioxidant and antityrosinase activities from litchi (Litchi sinensis Sonn.) seeds. Food Chem.
116:1-7.

Naveena, B. M., A. R. Sen, S. Vaithiyanathan, Y. Babji and N. Kondaiah. 2008. Comparative efficacy of pomegranate juice, pomegranate rind powder extract and BHT as antioxidants in cooked chicken patties. Meat Sci. 80:1304-1308.

Olivo, R., A. L. Soares, E. I. Ida and M. Shimokomaki. 2001. Dietary vitamin E inhibits poultry PSE and improves meat functional properties. J. Food Biochem. 25:271-283.

Oyaizu, M. 1986. Studies on products of browning reaction: Antioxidative activities of products of browning reaction prepared from glucosamine. Jap. J. Nutr. 44:307-315.

Park, C. I. and Y. J. Kim. 2008. Effects of dietary mugwort powder on the VBN, TBARS, and fatty acid composition of chicken meat during refrigerated storage. Korean J. Food Sci. An. 28:505-511.

Priscilla, D. H. and P. S. M. Prince. 2009. Cardioprotective effect of gallic acid on cardiactroponin-T, cardiac marker enzymes, lipid peroxidation products and antioxidants in experimentally induced myocardial infarction in Wistar rats. Chem-Biol. Interact. 179:118-124.

Rodriguez-Vaquero, M. J., M. R. Alberto and M. C. Manca de Nadra. 2007. Antibacterial effect of phenolic compounds from different wines. Food Control 18:93-101.

Rowe, L. J., K. R. Maddock, A. Trenkle, S. M. Lonergan and E. Huff-Lonergan. 2004. Oxidative environments decrease tenderization of beef steaks through inactivation of calpain. J. Anim. Sci. 82:3254-3266.

Russo, G. L. 2009. Dietary $n-6$ and $n-3$ polyunsaturated fatty acids: From biochemistry to clinical implications in cardiovascular prevention. Biochem. Pharmacol. 77:937-946.

Schlesier, K., M. Harwat, V. Bohm and R. Bitsch. 2002. Assesment of antioxidant activity by using different in vitro methods. Free Radical Res. 36:177-187.

Scislowski, W., D. Bauchart, D. Gruffat, P. M. Laplaud and D. Durand. 2005. Effects of dieraty n-6 or n-3 polyunsaturated fatty acids protected or not against ruminal hydrogenation on plasma lipids and their susceptibility to peroxidation in fattening steers. J. Anim. Sci. 83:2162-2174.

Sim, J. S. and G. H. Qi. 1995. Designing poultry products using flaxseed. In: Flaxseed in human nutrition (Ed. L. U. Thompson, and S. Cunnane) (pp. 315-333), Champaign: American Oil Chemist's Society Press.

Simitzis , P. E., S. G. Deligeorgis, J. A. Bizelis, A. Dardamani, I. Theodosiou and K. Fegeros. 2008. Effect of dietary oregano oil supplementation on lamb meat characteristics. Meat Sci. 79:217-223.

Subramanian, K. N., G. Padmanaban and S. Sarma. 1965. FolinCiocalteu reagent for the estimation of siderochromes. Anal. Biochem. 12:106-112.

Tudor, G. D., F. J. Couper and D. W. Pethick. 1996. Effect of silage diet on glycogen concentration in the muscle of yearling cattle. Proc. Aust. Soc. Anim. Prod. 21:451.

Zelenka, J., D. Schneiderova, E. Mrkvicova and P. Dolezal. 2008. The effect of dietary linseed oils with different fatty acid pattern on the content of fatty acids in chicken meat. Vet. Med. 53:77-85.

Zhang, W., S. Xiao, H. Samaraweera, E. J. Lee and D. U. Ahn. 2010. Improving functional value of meat products. Meat Sci. $86: 15-31$ 